\title{
Time for change? An evaluation of integrated cervical screening and HPV immunization programs in Canada
}

Stephen P. Tully ${ }^{1}$, Andrea M. Anonychuk ${ }^{2,3}$, Diana Maria Sanchez ${ }^{4}$, Alison P. Galvani ${ }^{4} \&$ Chris T. Bauch ${ }^{1,5^{*}}$

1: Department of Mathematics and Statistics, University of Guelph, Canada

2: Leslie Dan Faculty of Pharmacy, University of Toronto, Canada

3: GlaxoSmithKline Biologicals, Wavre, Belgium

4: School of Public Health, Yale University, USA

5: Department of Epidemiology, Biostatistics and Occupational Health, McGill University, Canada

Revised version submitted to Vaccine March 4, 2011

Original version submitted to Vaccine August 30, 2010

* Author for correspondence: Chris T. Bauch, cbauch@uoguelph.ca. Department of Mathematics and Statistics, University of Guelph, 50 Stone Road East, Guelph, ON

N1G 2W1, Canada. Fax: 519-837-0221. Phone: 519-824-4120 


\section{$\underline{\text { Abstract }}$}

Many jurisdictions have implemented universal human papillomavirus (HPV) immunization programs in preadolescent females. However, the cost-effectiveness of modified cervical screening guidelines and/or catch-up immunization in older females in Canada has not been evaluated. We conducted a cost-utility analysis of screening and immunization with the bivalent vaccine for the Canadian setting from the Ministry of Health perspective. We used a dynamic model to capture herd immunity and included cross-protection against strains not included in the vaccine. We found that adding catch-up immunization to the current program would be costeffective, and that combining such vaccination with delaying the start age of screening could result in cost savings.

Key words: human papillomavirus vaccine, catch-up immunization, dynamic model, cervical screening, cervical cancer, economic evaluation 


\section{Introduction}

Cervical cancer continues to impose a considerable burden worldwide despite reduced incidence after the implementation of cervical cancer screening in the 1960s (1,2). In 2009 alone, an estimated 1,300 women were diagnosed with cervical cancer and approximately 390 women died of this disease in Canada (3). Among women aged 20-44 years, it is the second most common type of cancer.

The guidelines for cervical cancer screening in Canada state that all women aged 18 and over should be screened, initially with two smears one year apart. If these smears are within normal limits, then rescreening every three years is advised until the age of 69 (4). The success of this program is reflected in the participation rate of women. The best national data currently available show 1-year participation rates do not vary greatly among provinces, ranging from $37 \%$ in British Columbia and Ontario to $44 \%$ in Nova Scotia with a 3-year participation rate of approximately $70 \%$ (5) across the country.

In the 1980s, infection by certain human papillomavirus (HPV) types was identified as a prerequisite for development of cervical cancer $(6,7)$. Approximately $70 \%$ of cervical cancer cases are caused by high-risk HPV types 16 and 18 (7). Recently, two vaccines against these high-risk types were developed that are effective in preventing HPV infection and development of pre-cancerous cervical lesions $(8,9)$. HPV vaccines are changing the landscape of cervical cancer prevention and treatment, with promise to reduce cervical cancer incidence still further.

Mathematical models can be used to project future costs and health outcomes of HPV immunization under various alternative immunization or screening strategies (10-32). These modeling studies have investigated topics such as 1) the costeffectiveness of universal HPV immunization in pre-adolescent females compared to no immunization; 2) the effectiveness of different immunization strategies in reducing prevalence of lesions and cervical cancer over time; 3) the costeffectiveness of vaccinating males; and 4) determining the number of women who need to be vaccinated to prevent one cervical cancer case or death. 
However, the implementation of universal immunization programs for preadolescent females in many jurisdictions has generated new questions regarding screening and immunization strategies. For example, how effective and costeffective, are catch-up immunization programs in older females who have not been vaccinated? Should screening recommendations change in response to the implementation of HPV immunization programs? What combined immunization/screening strategies are most effective for preventing cervical cancer and provide the best value for money? Moreover, emerging data from clinical trials may impact model predictions. For example, both bivalent and quadrivalent vaccines now report significant cross-protection against infection and high-grade lesions caused by high-risk HPV types not included in the vaccine $(8,33)$.

We address these new questions through a cost-utility analysis based upon a dynamic (transmission) model. Cost utility analyses estimate the costs required per quality-adjusted-life-year gained by implementing an alternative strategy, relative to the current strategy. Transmission models are useful for capturing transmission mechanisms and hence herd immunity effects, which can alter cost-effectiveness estimates considerably $(34,35)$. We parameterized the model with recently published data on cross-protection properties of the bivalent vaccine. Despite being recently licensed for use in Canada, the bivalent vaccine is not as well evaluated as the quadrivalent vaccine. Our model is tailored as closely as possible to Canada, where many provinces have implemented universal school-based programs and where a single payer (the ministry of health) is often responsible for supporting both immunization programs and cervical screening programs.

\section{$\underline{\text { 2. Methods }}$}

\subsection{Model structure}


An age-structured compartmental model of HPV transmission and immunization with the bivalent vaccine was developed. The population was stratified by age (1519, 20-24, 25-34, 35-44, 45-54, 55-64, 65+), gender (male, female), disease status (for females: susceptible, infected, natural immunity, vaccine immunity, cervical intraepithelial (CIN) grade 1 lesion, CIN2/3 lesion, or squamous cell carcinoma (SCC); for males: susceptible, infected, or natural immunity); and HPV type (16/18, or other high-risk). All transitions for demographic processes, natural disease history, infection and immunization are illustrated in Figure 1 for type 16/18 infection in a typical age class of females and males. The parameter definitions and parameter values corresponding to each transition are in Tables 1 and 2, and costing parameters are in Table 3, together with the data sources $(1,8,17,19,20$, 36-68). Full model equations are included in the Supplementary File (Sections S1 and S2).

\subsection{Demographic processes}

Males and females were recruited (i.e., entered the model population) at age 15. (The average age of onset of sexual intercourse is approximately 14-15 in the general Canadian population (69); vaccination at age 12 was accounted for by adjusting the compartmental sizes upon recruitment as required.) The size of each birth cohort equaled the average size of a typical Ontario birth cohort. Age-specific death rates due to other causes were applied to males and females. Age-specific benign hysterectomies were also included for females.

\subsection{Natural disease history assumptions}

Progression from infected to CIN1, infected to CIN2/3, and CIN1 to CIN2/3 occurred at specified rates. Regression also occurred from CIN1 to infected, CIN2/3 to CIN1 and CIN2/3 to infected at specified rates. Individuals cleared the infected state at a specified rate, acquiring natural immunity. Natural immunity to HPV is weak (39, 40), hence we assumed that individuals lost natural immunity at a specified rate, becoming fully susceptible again. Individuals progressed from CIN2/3 to squamous cell carcinoma (SCC) at a specified rate, and SCC did not regress. A separate 
submodel tracked progression from SCC stage I to SCC stage IV (see Supplementary File Section S3). The output of this submodel was used to assign a cost and QALY penalty per incident case of SCC, which was combined with the incidence of SCC predicted by the dynamic model to predict the total impact of SCC on costs and QALYs over time. Replacement effects caused by “unmasking"-progression of other-high-risk lesions that would have been removed through treatment in the prevaccine era-were also included and depended on the assumed vaccine coverage rate $(37,52)$ (Supplementary File, Section S4). It was assumed that progression of type 16/18 infections and progression of other high-risk types were otherwise independent.

\subsection{Transmission assumptions}

It was assumed that sexual mixing was age-assortative, with males and females tending to pick sexual partners close in age, but the male typically being a few years older than the female (38). For type 16/18 infection, the probability of a susceptible female of age group $i$ being infected by an infected male of age group $j$ depended on (1) the proportion of contacts of females in age group $i$ that occurred with males in age group $j$ according to the age-assortative mixing considerations; (2) the percentage of males in age group $j$ currently infected; and (3) a fitted parameter representing the transmission rate. The transmission rate parameter was further adjusted for age-related and gender-related differences (male to female versus female to male) in transmission probability. Age-related variation was allowed because epidemiologically relevant factors such as frequency of sexual intercourse, partnership turnover rate, and sexual network structure also vary with age $(38,70$, 71). The free parameters were fitted according to a filtering methodology described in subsection 2.7. Transmission was modeled the same way for infection by other high-risk types, and for the rate at which females infected males. The mathematical equations representing the transmission processes appear in the Supplementary File, Sections S1 and S2.

\subsection{Intervention assumptions}


Individuals efficaciously vaccinated were moved from the susceptible to the vaccine immunity compartment. We assumed use of the bivalent vaccine: this vaccine has a high efficacy against infection for type 16/18, and also provides partial efficacy against infection and CIN2/3 lesions associated with high-risk types not included in the vaccine. The efficacy of the vaccine in preventing CIN2+ lesions by twelve common non-16/18 high-risk types is 37\% after adjusting for co-infections (54\% before adjusting for co-infections) (8). In the model, this cross-protection was incorporated by assuming a specified vaccine efficacy against infection by other high-risk types (thereby allowing us to capture herd immunity effects), with an additional efficacy parameter for preventing CIN2+ lesions, to account for cases where the vaccine prevented lesions caused by other-high risk types but did not prevent infection (this was modeled as a reduced rate of progression from infection to lesions). For the baseline analysis we assumed a lifelong duration of vaccinederived immunity, but we considered a scenario of waning immunity in sensitivity analysis. Screening could occur at any point during disease progression, but only detected CIN2/3 and SCC were treated (CIN1 was assumed to be monitored only). Stage-specific sensitivity and specificity for the Pap test were assumed. Most individuals treated for CIN2/3 were moved to the susceptible state, and the remainder was moved to the infected state (68). Screening was assumed to occur at age-specific rates that have been actually observed, rather than at the recommended screening intervals. We assumed that vaccine coverage under a school-based program would be higher than vaccine coverage under a clinic-based program, based on experience with hepatitis B immunization in Canada (72-74).

\subsection{Health economic assumptions and costs}

An 80-year time horizon was used, with a 3\% discount rate applied to both costs and health outcomes (75). Disutility scores for false positive outcomes, and CIN or cervical cancer diagnoses, were applied over a specified duration (Table 3). A fullcourse of vaccine was assumed to cost \$270 CAD (67), and vaccine administration 
costs were different for clinic-based versus school-based settings. The Ministry of Health perspective, as the single payer, was adopted. Costing data (Table 3) were based on Canadian data where possible and were inflated to 2010 Canadian dollars using the healthcare component of the Consumer Price Index for reporting results.

Reported outcomes were: (1) total incidence of squamous cell carcinoma 10, 30, and 60 years after the start of immunization programs in 2007; (2) incremental average annual undiscounted costs of alternative strategies versus current practice; (3) costs per quality-adjusted-life-year (QALY) gained; (4) costs per life-years saved. We also projected squamous cell carcinoma incidence over time under several strategies.

\subsection{Comparators}

Eight comparator strategies (Table 4) were divided into two categories according to the baseline strategy against which they were compared: (1) immunization strategies compared to no vaccination (i.e. screening only); (2) individual or combined immunization and screening strategies being compared to immunization of $80 \%$ of 12 -year-old females in a school-based program and current screening (21, 76). We assumed three doses of vaccine were administered. Two types of catch-up programs were considered. Under the "school-based catch-up program", a schoolbased program covers $80 \%$ of 18 -year-olds females until the first cohort vaccinated at age 12 reaches the age of 18 , at which point the catch-up program is no longer needed. Under the "clinic-based catch-up program", a catch-up program is administered through physician offices and public health clinics, and is targeted at females aged 12-26. It was assumed that a clinic-based catch-up program covers $40 \%$ of females over a three-year period.

\subsection{Parameterization and sensitivity analysis}

HPV transmission and natural history are highly uncertain, such that multiple parameter combinations may explain data on HPV infection prevalence and SCC incidence almost equally well. To deal with this uncertainty, a probabilistic 
uncertainty analysis based on filtering outputs from Monte Carlo sampling was used to decide which parameter values to use to generate results. For each parameter subject to significant uncertainty, an interval of lowest and highest plausible values was defined based on existing literature (see Tables 1-3 for intervals). The model was then simulated 100,000 times. For each simulated parameter realization, samples were drawn from a triangular distribution for each input parameter for which a plausible interval was defined. The lower and upper limits of the triangular distribution were based on the lowest and highest plausible values. The output of each simulated realization was then compared to empirical data on (1) overall prevalence of infection by type 16/18; (2) overall prevalence of infection by other high-risk types; (3) prevalence of infection by any high-risk type by age; (4) incidence of SCC by age class $(1,17,19,41)$. Acceptance ranges were defined based on these empirical data (see Table 2 for ranges used). All realizations that fell outside of at least one acceptance range were discarded. The remaining set of 223 parameter values was used to generate results. The fit of the model to the acceptance ranges defined from the data is shown in the Supplementary File, Section S5.

We also conducted a univariate sensitivity analysis for all comparators described in Table 4 under scenarios where parameters differed from the baseline assumptions, including (1) lower baseline coverage of $60 \%$ and $40 \%$ under the universal schoolbased program in females aged 12 years (with clinic-based coverage of $30 \%$ and $20 \%$ respectively) (2) a 3\% rate of waning vaccine-derived immunity, (3) no vaccine cross-protection, (4) natural immunity lasting 15 years, and 40 years, and (5) vaccine cost of $\$ 400$ for a full course of 3 doses. We also plotted cost-effectiveness of some comparators against the assumed cost for a full course of vaccination.

\section{Results}


Our modeling shows that school-based immunization of $80 \%$ of females at age 12 is cost-effective compared to no immunization (scenario 1), yielding an incremental cost-utility ratio below a threshold of \$50,000/QALY (77). Adding school-based catch-up immunization of $80 \%$ of females at age 18 (scenario 2) is also cost-effective at this threshold (Table 5). These results are robust under the probabilistic uncertainty analysis. The cost per QALY gained is always lower than the cost per life-year saved because QALY gains under vaccine programs are partially due to preventing lesions that would have otherwise reduced quality of life, without necessarily leading to cancer-related deaths. Long-term SCC incidence is reduced significantly in both scenarios 1 and 2 .

Addition of either a clinic-based or a school-based catch-up program to the baseline practice of vaccinating $80 \%$ of age 12 females in a school-based program is also cost-effective (scenarios 3 and 4). Moreover, the incremental cost-effectiveness ratios of scenarios 3 and 4 are lower than that of the comparator in scenario 1 because catch-up immunization targets older women, thereby preventing lesions and SCC cases sooner than would immunization at age 12. As a result, health gains under catch-up programs are less impacted by discounting.

School-based catch-up is predicted to be more cost-effective than clinic-based catchup, although total SCC incidence declines more rapidly and QALY gains accrue more rapidly under clinic-based catch-up than under school-based catch-up. SCC incidence declines more quickly under either catch-up program than under the baseline scenario of vaccinating 12-year-old females only (scenario 1). However, catch-up immunization does not impact total SCC incidence in the very long term: after 60 years, peak SCC incidence is occurring in birth cohorts that were born well after the catch-up program was phased out.

In the presence of an immunization program covering $80 \%$ of 12 -year-old females, delaying the initial screening age to either 21 or 25 results in significant cost savings compared to current screening practices (scenarios 5 and 6). However, the uncertainty intervals on incremental QALYs are very large since QALY gains from 
reducing false positives under these strategies do not necessarily counteract QALY losses from slightly increased progression to cancer. Hence it is not clear whether delaying the initial screening age alone is dominated, or dominates, current practice from a QALY perspective. Delaying the initial screening age also results in a small but definite net loss of life-years, meaning delaying strategies are dominated by the current practice with respect to life-years saved. SCC incidence increases slightly under these strategies, relative to continuing the current screening practice. Cost savings are significantly larger under a strategy of initial screening at age 25 than under a strategy of initial screening at age 21.

We also considered two combined strategies that implement catch-up immunization while simultaneously changing screening recommendations (scenarios 7 and 8). These strategies are predicted to save costs while also generating significant QALY gains (Table 5). Thus, these strategies dominate the current strategy. This outcome is robust under our probabilistic uncertainty analysis. The most cost-saving strategy, which is also the most effective in reducing SCC incidence and gaining QALYs, is implementing a clinic-based catch-up program in women aged 13-26 while simultaneously delaying initial screening until the age of 25 . This strategy is cost saving because it reduces screening in an age group that is at low risk of developing SCC, while simultaneously expanding vaccine coverage in these age groups. The strategy is highly effective because the vaccine covers a wider range of ages and because herd immunity benefits compensate for lower vaccine coverage compared to the school-based catch-up program. (Herd immunity benefits can be expected to be significant at $40 \%$ coverage for an infection such as HPV.) Combined strategies involving school-based catch-up are somewhat less cost saving and accrue fewer QALYs than clinic-based catch-up programs, but are still economically attractive.

The time evolution of SCC incidence in all strategies remains relatively constant from 2007 until 2017, after which SCC incidence begins to decline as larger numbers of individuals in vaccinated birth cohorts become sexually active (Figure 2). SCC incidence due to all high-risk HPV types declines to about 2 per 100,000 women per 
year by the year 2050, for strategies without catch-up. For strategies with a clinicbased catch-up program the same level of incidence of 2 per 100,000 women is reached a decade earlier, in 2040. The decline is particularly rapid between the years 2017 and 2037. Changing the initial screening age to 25 years does not have a significant impact on the temporal trajectory of total SCC incidence in any strategy (Figure 2).

The probabilistic uncertainty analysis yields confidence intervals that support robustness of model predictions under uncertainty in parameters relating to disease natural history, transmissibility and treatment costs. However, it is also useful to conduct univariate sensitivity analysis on crucial individual parameters to understand their specific impact on predictions, such as vaccine coverage, waning vaccine immunity, vaccine cross-protection, duration of natural immunity, and vaccine cost (Supplementary File, Sections S6-S13). We find that vaccine price is an important driver of estimated cost-effectiveness (Figure 3 and Supplementary File, Section S6). For instance, as the cost of 3 doses of vaccine decreases from $\$ 400$ to $\$ 150$, the incremental cost-effectiveness ratio (ICER) for catch-up immunization under the clinic-based program (scenario 4) decreases from $\$ 12,000 /$ QALY to $\$ 6,000 /$ QALY (Figure 3). The relative change in the ICER is similar for scenarios 1 and 3 (Figure 3).

If the assumed baseline vaccine coverage in school-based programs in 12-year-old females is changed from $80 \%$ to $60 \%$ or $40 \%$, the incremental cost-effectiveness ratios are lower across all scenarios (Sections S7 and S8). This reflects the higher incremental benefits of vaccine-derived herd immunity at intermediate vaccine coverage versus high vaccine coverage. Results are otherwise qualitatively unchanged. Allowing vaccine-derived immunity to wane at 3\% per year has relatively little impact on the results (Section S9). Removing vaccine crossprotection results in a moderate increase in incremental cost-effectiveness ratios, in line with what is known from clinical studies on cross protection (Section S10) (8). Assuming a longer duration of natural immunity of 15 years on average, or 40 years on average, has a significant impact on predicted cost-effectiveness (Sections S11 
and S12); however, the median ICER for catch-up immunization scenarios remains below $\$ 50,000 / Q A L Y$ even when natural immunity lasts 40 years. A conservative scenario that changes three parameters-higher vaccine cost ( $\$ 400$ for 3 doses), no cross-protection from the vaccine, and longer-lasting natural immunity (40 years)increases the median incremental cost-effectiveness ratio to $\$ 20,756 /$ QALY for clinic-based catch-up (scenario 4) and to \$20,342/QALY for school-based catch-up (scenario 3) (Section S13).

\section{Discussion}

Here we assessed the effectiveness and cost-effectiveness of catch-up HPV immunization and modified screening programs, compared to current school-based immunization at age 12 and current screening practices. We also assessed effectiveness and cost-effectiveness of school-based immunization at age 12 to no immunization (current screening only) in order to compare our model to other published models that have assessed that comparator. Our dynamic model was largely parameterized from Canadian data sources and included herd immunity effects, as well as cross-protection observed with the bivalent vaccine against highrisk types not included in the vaccine. We found that both clinic-based and schoolbased catch-up immunization strategies are cost-effective at $\$ 50,000 / Q A L Y$. The higher cost-effectiveness of these strategies compared to strategies that vaccinate at age 12 derives partially from preventing outcomes sooner than strategies that vaccinate at a younger age, despite the fact that immunization in older age groups may occur after infections have occurred. Delaying initial screening until age 21 or 25 saves costs but may not result in net QALY gains if the harms of preventing slightly less cervical cancer in these age groups outweigh the benefits of avoiding numerous false positives. These strategies also cause small increases in SCC incidence and life-years lost. However, delaying the initial age of screening while also implementing catch-up immunization is predicted to save costs, reduce SCC incidence, and accrue more QALYs, compared to current screening practice and a 
program of only immunizing females at age 12 (scenarios 7 and 8, Table 5). These results are robust under the ranges used in our probabilistic uncertainty analysis. Univariate sensitivity analysis showed that results were most sensitive to assumptions about vaccine cost and durability of natural immunity.

The predicted cost per QALY gained under universal HPV immunization of preadolescent females compared to no immunization (scenario 1) varies widely across published analyses. A large number of model assumptions can potentially influence both costs and effectiveness $(22,24,28)$. Our predicted cost-effectiveness ratio for universal immunization versus no immunization is lower than that found in two similar comparisons in the Canadian setting. These two studies did not account for herd immunity and cross-protection and/or assumed a higher vaccine cost. By comparison, our analysis includes herd immunity, vaccine cross protection, and a lower vaccine cost, which may explain why our predicted ICER is lower $(20,21)$. Our estimates are also somewhat lower than similar comparisons in other countries: country-specific factors may drive differences in predicted costeffectiveness $(23,25)$. Among analyses that use dynamic models, our estimates produce lower cost-effectiveness ratios than some $(23,25)$ but higher costeffectiveness ratios than others $(29-31,38)$. Our baseline assumption of $\$ 270$ for 3 doses of vaccine is based on the most recent price of the bivalent vaccine Cervarix ${ }^{\circledR}$ for the private Canadian market (the public health price will probably be lower than this). Previous modelling analyses have typically assumed a cost of $\$ 400$ for 3 doses of vaccine, and sensitivity analysis of our model as well as many previous models suggests that vaccine cost is an important driver of estimated cost-effectiveness of universal HPV immunization. Our predicted ICER for universal preadolescent immunization versus no immunization for the case that combines no crossprotection, a higher vaccine cost of $\$ 400$, and long-lasting natural immunity (Supplemental File, Section S13) is $\$ 32,370 /$ QALY, which is significantly higher than the ICER for our baseline (scenario 1), and is closer to some of the higher ICER estimates that have been published $(23,25)$. The detrimental impact of waning immunity (Supplementary File, Section S9) is generally not as high as predicted by 
some other modeling analyses based on static models (20). We attribute this to the inclusion of herd immunity in our model. A previous model-based analysis comparing cost-effectiveness with/without herd immunity and with/without waning vaccine immunity shows that waning immunity impacts cost-effectiveness ratios less when herd immunity is included than when it is not (21). We note that durability of natural immunity is a determinant of strength of herd immunity generated by vaccines, and by extension the impact of waning vaccine immunity $(22,27)$.

As for any model, this model had certain limitations that must be borne in mind when interpreting its results. For instance, we did not include distinct risk groups, although the risk of HPV infection varies with sexual activity level (78). We used 5year age intervals in the model based on age intervals in available data, despite the fact that HPV epidemiology can vary significantly within 5-year age intervals. Individuals transition at a constant rate between ages and epidemiological compartments, which means that some outcomes such as SCC incidence reduction may occur sooner in the model than they would in reality: this effect will lower the incremental cost-effectiveness ratios once discounting is applied. We assumed independence between screening adherence and vaccine coverage, although in reality the likelihood of undergoing regular screening may not be independent of the likelihood of accepting immunization (79) and such heterogeneities can significantly impact results. If low vaccine uptake is markedly positively correlated with low screening adherence, then cost-effectiveness ratios will likely be higher than we predicted. We did not include the possibility of strain replacement (32), as thus far there is no evidence for strain replacement. It would be difficult to address the impact of strain replacement even via sensitivity analysis, because so little is known about its possible likelihood, extent and impact. In principle, strain replacement is less pertinent to HPV than to many other vaccine-preventable infections, as the significant lag between HPV infection and cancer development allows time to reformulate the vaccine and administer booster doses. We also did not incorporate a screening algorithm. This means that the model could not be used 
to assess the impact of certain alternative screening algorithms. However, not including a screening algorithm will have little impact on our prediction of cost savings when catch-up vaccination is combined with a delay in the initial age of screening (scenarios 7 and 8), because the incidence of CIN lesions and cancer is small before the ages of 21 or 25 , and the cost savings of this strategy are driven by not having to do Pap testing below these ages. Like many other models, our model grouped multiple HPV types into the same categories for simplicity; this forces an artificially high parameterized transmissibility, which in turn tends to yield more conservative predictions of the impact of vaccination (22). We also assumed that vaccine efficacy was the same in older women with previous exposure to HPV than in younger women without previous exposure. Finally, consistent with many other HPV dynamic models, we did not account for the existence of sexual partnerships, which can likewise influence projections under certain conditions $(26,70,80)$. These limitations suggest directions for future work using more sophisticated models.

For many jurisdictions, recently implemented HPV immunization programs in preadolescent females are among the most expensive immunization programs ever introduced. Although implementation costs are high in absolute terms, our analysis suggests that these programs are cost-effective compared to no immunization, and significantly reduce costs associated with follow-up screening, and treatment of high-grade lesions and cancer. Moreover, adding catch-up immunization in older females to an existing program in 12-year-old females is cost-effective compared to continuing with the program in 12-year-old females only. Finally, in jurisdictions where a single payer is responsible for the reimbursement of both HPV immunization programs and cervical screening programs, implementing catch-up programs combined with delaying the initial age of screening can result in significant cost-savings - with greater costs of the immunization program being offset by reduced costs associated with cervical screening - while also providing additional health benefits. 


\section{Conclusions}

Catch-up HPV immunization of females, either through a school-based program or a clinic-based program, is predicted to be cost-effective in the Canadian setting. From the Ministry of Health perspective, it provides additional health benefits at a cost considered acceptable by commonly used cost-effectiveness standards. Moreover, combining catch-up immunization with a delay in the age of initial screening is predicted to be cost saving from the Ministry of Health perspective while also providing additional health benefits. Our model included herd immunity effects, vaccine cross-protection, and the most recent information on reduced cost of the bivalent vaccine, all of which have a significant impact on predicted cost per QALY gained.

\section{Acknowledgements}

CTB was supported by an Ontario Ministry of Research and Innovation Early Researcher Award with matching funds from GlaxoSmithKline Canada, an operating grant from the Canadian Institutes of Health Research (CIHR), and a CIHR New Investigator Award. APG was supported by the James S. McDonnell Foundation. The funders had no role in developing the research questions, conducting the research, or the decision to submit the paper. The authors are grateful to Chander Sehgal for helpful comments. 


\section{$\underline{\text { References }}$}

1. Sanjose S, Diaz M, Castellsague X, Cliffofrd G, Bruni L, Munoz N, et al. Worldwide prevalence and genotype distribution of cervical human papillomavirus DNA in women with normal cytology: a meta-analysis. Lancet Infect Dis. 2007;7:453-9.

2. Vizcaino A, Moreno V, Bosch F, Munoz N, Barros-Dios Z, Borras J, et al. International trends in incidence of cervical cancer II. Squamous-cell carcinoma. Int J Cancer. 2000;86:429-35.

3. Canadian Cancer Statistics 2009. Special topic: Cancer in adolescents and young adults. Toronto: Canadian Cancer Society2009.

4. Programmatic guidelines for screening for cancer of the cervix in Canada. Society of Gynecologic Oncologists of Canada1998.

5. Cervical cancer screening in Canada: 1998 surveillance report. Health Canada. http://www.phac-aspc.gc.ca/publicat/ccsic-dccuac/index-eng.php. 2002.

6. Durst M, Gissmann L, Ikenberg H, zurHausen H. A papillomavirus DNA from a cervical carcinoma and its prevalence in cancer biopsy samples from different geographic regions. Proc Natl Acad Sci USA. 1983;80:3812-5.

7. Bosch FX, Manos MM, Munoz N, Sherman M, Jansen AM, Peto J. Prevalence of human papillomavirus in cervical cancer: a worldwide perspective. Journal of the National Cancer Institute. 1995;87(11):796-802.

8. Paavonen J, Naud P, Salmeron J, Wheeler C, Chow S, Apter D. Efficacy of human papillomavirus (HPV)-16/18 AS04-adjuvanted vaccine against cervical infection and precancer caused by onogenic HPV types (PATRICIA): final analysis of a double-blind, randomised study in young women. The Lancet. 2009;374:301-14.

9. Villa LL, Costa RL, Petta CA, Andrade RP, Ault KA, Giuliano AR. Prophylactic quadrivalent human papillomavirus (types 6,11,16, and 18) L1 virus-like particle vaccine in young women: a randomised double-blind placebocontrolled multicentre phase II efficacy trial. The Lancet Oncology. 2005;6(5):271-8.

10. Bauch CT, Li M, Chapman G, Galvani AP. Adherence to cervical screening in the era of human papillomavirus vaccination: how low is too low? . Lancet Inf Dis. 2010;10(133-137).

11. Garnett GP, Kim JJ, French K, Goldie SJ. Chapter 21: Modelling the impact of HPV vaccines on cervical cancer and screening programmes. Vaccine. 2006;24 Suppl. 3:S178-S86.

12. Barnabas RV, Laukkanen P, Koskela P, Kontula O, Lehtinen M, Garnett G. Epidemiology of HPV 16 and cervical cancer in Finland and the potential impact of vaccination: mathematical modelling analyses. PLoS Medicine. 2006;3(5):624-32.

13. Hughes JP, Garnett GP, Koutsky L. The theoretical population-level impact of a prophylactic human papillomavirus vaccine. Epidemiology 2002;13(6):631-9. 
14. Dasbach E, Elbasha E, Insinga R. Mathematical models for predicting the epidemiologic and economic impact of vaccination against human papillomavirus infection and diseases. Epidemiologic reviews. 2006;28(1):88-100.

15. Elbasha EH, Dasbach EJ, Insinga RP. Model for assessing human papillomavirus vaccination strategies. Emerging infectious diseases. 2007;13(1):28-41.

16. Goldie SJ, Grima D, Kohli M, Wright TC, Weinstein M, Franco E. A comphrehensive natural history model of HPV infection and cervical cancer to estimate the clinical impact of a prophylactic HPV-16/18 vaccine. International Journal of Cancer. 2003;106:896-904.

17. van de Velde N, Brisson M, Boily M. Modeling Human Papillomavirus Vaccine Effectiveness: Quantifying the Impact of Parameter Uncertainty. American Journal of Epidemiology. 2007;165(7):762-75.

18. Burchell A, Richardson H, Mahmud S. Modeling the sexual transmissibility of HPV infection using stochastic computer simulation and empirical data from a cohort study of young women in Montreal. Canada. American Journal of Epidemiology. 2006;163(6):534-43.

19. Brisson M, van de Velde N, Boily MC, de Wals P. Estimating the number needed to vaccinate to prevent HPV related disease and mortality. Canadian Medical Association Journal. 2007;177:464-8.

20. Brisson M, van de Velde N, de Wals P, Boily MC. The potential costeffectiveness of prophylactic human papillomavirus vaccines in Canada. Vaccine. 2007;25(29):5399-408.

21. Anonychuk AM, Bauch CT, Merid MF, VanKriekinge G, Demarteau N. A costutility analysis of cervical cancer vaccination in preadolescent Canadian females. BMC Public Health. 2009;9:401.

22. Van de Velde N, Brisson M, Boily M. Understanding differences in predictions of HPV vaccine effectiveness: a comparative model-based analysis. Vaccine. 2010;28(33):5473-84.

23. Usher C, Tilson L, Olsen J, Jepsen M, Walsh C, Barry M. Cost-effectiveness of human papillomavirus vaccine in reducing the risk of cervical cancer in Ireland due to HPV types 16 and 18 using a transmission dynamic model. Vaccine. 2008;26:5654-61.

24. Newall AT, Beutels P, Wood JG, Edmunds WJ, MacIntyre C. Cost-effectiveness analyses of human papillomavirus vaccination. The Lancet Infectious Diseases. 2007;7(4):289-96.

25. Torvinen S, Nieminen P, Lehtinen M, Paavonen J, Demarteau N, Hahl J. Cost effectiveness of prophylactic HPV 16/18 vaccination in Finland: results from a modelling exercise. J Medical Economics. 2010;13(2):284-94.

26. Muller H, Bauch CT. When do sexual partnerships need to be accounted for in transmission models of human papillomavirus? Int J Env Research and Public Health. 2010;7(2):635-50.

27. Garnett GP. Role of Herd Immunity in Determining the Effect of Vaccines against Sexually Transmitted Disease. Journal of infectious Diseases. 2005;191:S97-S106. 
28. Marra F, Cloutier K, Oteng B, Marra C, Ogilvie G. Effectiveness and costeffectivenes of human papillomavirus vaccine: a systematic review. PharmacoEconomics. 2009;27(2):127-47.

29. Elbasha EH, Dasbach EJ, Insinga RP, Haupt RM, Barr E. Age-based programs for vaccination against HPV. Value in Health. 2009;12(5):697-707.

30. Debicki D, Ferko N, Demarteau N, Gallivan S, Bauch C, Anonychuk A, et al. Comparison of detailed and succinct cohort modelling approaches in a multiregional evaluation of cervical cancer vaccination. Vaccine. 2008;15:F16-F28.

31. Olsen J, Jepsen MR. Human papillomavirus transmission and cost-effectivness of introducing quadrivalent HPV vaccination in Denmark. Int J Tech Asses in Health Care. 2010;26:183-91.

32. Elbasha EH, Galvani AP. Vaccination against multiple HPV types. Mathematical Biosciences. 2005;197:88-117.

33. Brown DR, Kjaer SK, Sigurdsson K, Iversen O, Hernandez-Avila M, Wheeler $\mathrm{CM}$, et al. The impact of quadrivalent human papillomavirus (HPV; Types 6, 11,16 , and 18) L1 virus-like particle vaccine on infection and disease due to oncogenic nonvaccine HPV types in generally HPV-naive women aged 16-26 years. J Infect Dis. 2009;199:926-35.

34. Edmunds W, Medley G, Nokes D. Evaluating the cost-effectiveness of vaccination programs: a dynamic perspective. Statistics in medicine. 1999;18(23):3263-82.

35. Brisson M, Edmunds W. Economic evaluation of vaccination programs: the impact of herd immunity. Medical Decision Making. 2003;23(1):76-82.

36. Drolet M, Brisson M, Maunsell E, Ferenczy A, Franco EL, Ratnam S, et al. Quality of life lost following an abnormal cervical cytology result: a prospective 3-month study. Eurogin 2010 Congress; Monte Carlo2010.

37. Insinga R, Glass A, Rush B. Diagnoses and outcomes in cervical cancer screening: a population-based study. Am J Obstet Gynecol. 2004;191:105-13.

38. Taira A, Neukermans C, Sanders G. Evaluating human papillomavirus programmes. Emerging infectious diseases. 2004;10(11):1915-23.

39. Ho G, Studentsov Y, Bierman R, Burk R. Natural history of human papillomavirus type 16 virus-like particle antibodies in young women. Cancer epidemiology, biomarkers \& prevention. 2004;13:110-6.

40. Carter J, Koutsky L, Wipf G. The natural history of human papillomavirus type 16 capsid antibodies among a cohort of university women. Journal of Infectious Disease. 1996;174:927.

41. Dunne EF. Prevalence of HPV infection among females in the United States. JAMA. 2006;297(8):813-9.

42. Viscidi R, Schiffman M, Hildesheim A, Herrero R, Castle P, Bratti M. Seroreactivity to human papillomavirus (HPV) types 16, 18 or 31 and risk of subsequent HPV infection. Cancer Epidemiology, Biomarkers \& Prevention. 2004;13:324.

43. StatCan. Statistics Canada Website, Canadian Statistics Section, Vital Statistics. http://wwwstatscanca. 2007.

44. CIHI. Canadian Institute for Health Information: Health Indicators 2009 (Ottawa, ON)2009. 
45. Webpage. Cervical cancer-survival statistics. Cancer Research UK; 2010 [June 18, 2010]; Available from:

http://info.cancerresearchuk.org/cancerstats/types/cervix/survival/index.h $\underline{\mathrm{tm}}$.

46. Davey C. 2003 CytoBase Report, Ammended [sic]. Toronto, Ontario: INSCYTE Corporation2003.

47. Mayrand M, Duarte-Franco E, Rodrigues I, Walter S, Hanley J, Ferenczy A. Human papillomavirus DNA versus Papanicolaou screening tests for cervical cancer. N Engl J Med. 2007;357:1579-88.

48. Fahey M, Irwig L, Macaskill P. Meta-analysis of Pap test accuracy. Am J Epidemiol 1995;141:680-9.

49. Karnon J, Peters J, Platt J, Chilcott J, McGoogan E, Brewer N. Liquid-based cytology in cervical screening: an updated rapid and systematic review and economic analysis. Health Technology Assessment. 2004;8(20):3-78.

50. Lier D, Jacobs P. An economic analysis of the introduction of liquid-based cytology (LBC) and human papillomavirus (HPV) testing in Alberta. A Report for the Alberta Cervical Cancer Screening Program: 2005. 2005.

51. Pretet J, Jacquard A, Carcopino X, Charlot J, Bouhour D, Kantelip B, et al. Human papillomavirus genotype distribution in invasive cervical cancers in France: EDITH study. Int J Cancer. 2008;122:428-32.

52. Pretet J, Jacquard A, Saunier M, Clavel C, Dachez R, Gondry K, et al. Human papillomavirus genotype distribution in low grade squamous intraepithelial lesions in France and comparison with CIN2/3 and invasive cervical cancer: The EDITH III study. Gynecologic Oncology. 2008;110:179-84.

53. Paavonen J, Jenkins D, Bosch XF. Efficacy of a prophylactic adjuvanted bivalent L1 virus-like-particle vaccine against infection with human papillomavirus types 16 and 18 in young women: an interim analysis of a phase III double-blind, randomised controlled trial. The Lancet. 2007;369(9580):2161-70.

54. Krahn M, McLachlin M, Pham B, Rosen B. Liquid-based techniques for cervical ccancer screening: systematic review and cost-effectiveness analysis. CADTH Study Report. 2007.

55. Marcus A, Kaplan C, Crane L, Berek J, Bernstein G, Gunning G, et al. Reducing loss-to-follow-up among women with abnormal Pap smears; results from a randomized trial testing an intensive follow-up protocol and economic incentives. Medical Care. 1998;36(3):397-410.

56. McLachlin CM, Fung MFK, Chambers A. Cervical screening: a clinical practice guideline. Cervical Cancer Screening Guidelines Committee of the Ontario Cervical Cancer Screening Program and the Gynecology Cancer Disease Site Group of Cancer Care Ontario Evidence-based series: Section 1. 2005.

57. Wagner E, Duggan M. Effectiveness of follow up-letters to health care providers in triggering follow-up for women with abnormal results on Papanicolaou testing. Canadian Medical Association Journal. 2001;164(2):207-8. 
58. Kahn J, Goodman E, Huan B, Slpa G, Emans S. Predictors of Papanicolau smear return in a hospital-based adolescent and young adult clinic. Obstetrics and Gynecology. 2003;101(3):490-9.

59. Maxwell G, Carlson J, Ochoa M, Krivak T, Rose G, Myers E. Costs and effectiveness of alternative strategies for cervical cancer screening in military beneficiaries. Obstetrics and Gynecology. 2002;100(4):740-8.

60. Bauch CT, Anonychuk AM, Pham BZ, Gilca V, Duval B, Krahn MD. Cost-utility of universal hepatitis A vaccination in canada. Vaccine. 2007;25(51):8536-48.

61. Mittman N, Trakas K, Risebrough N. Utility score for chronic conditions in a community-dwelling population. PharmacoEconomics. 1999;15:369-76.

62. Darroch JE, Landry DJ, Oslak S. Age differences between sexual partners in the United States. Family Planning Perspectives. 1999;31(4):160-7.

63. Nanda K, McCrory DC, Myers ER, Bastian LA, Hasselbad V, Hickey JD, et al. Accuracy of the Papanicolaou test in screening for and follow-up of cervical cytologic abnormalities: a systematic review. Ann Intern Med. 2000;132(10):810-9.

64. Karnon J, Peters J, Platt J, Chilcott J, McGoogan E, Brewer N. Liquid-based cytology in cervical screening: an updated rapid and systematic review and economic analysis. Health Technol Assess. 2004;8(20):1-78.

65. Insinga RP, Glass AG, Myers ER, Rush BB. Abnormal outcomes following cervical cancer screening: event duration and health utility loss. Medical Decision Making. 2007;27(4):414-22.

66. Munoz N, Bosch FX, Castellsague X, Diaz M, deSanjose S, Hammouda D, et al. Against which human papillomavirus types shall we vaccinate and screen?

The international perspective. Int J Cancer. 2004;111:278-85.

67. Hirschler B. Glaxo cuts Cervarix price by 30 pct in Canada. Reuters, http://wwwreuterscom/article/2010/10/25/glaxo-cervarixidCALDE69010P20101025. 2010.

68. Kreimer A, Katki H, Schiffman M, Wheeler C, Castle P. Viral determinants of human papillomavirus persistence following loop electrical excision procedure for treatment of Cervical Intraepithelial Neoplasia Grade 2 or 3. Cancer epidemiology, biomarkers \& prevention. 2007;16:11-6.

69. "Council of Ministers of Education C. Canadian youth, sexual health and HIV/AIDS study: Factors influencing knowledge, attitudes and behaviours. Toronto2003.

70. Kretzschmar M. Sexual Network Structure and Sexually Transmitted Disease Prevention: A Modeling Perspective. Sexually Transmitted Diseases. 2000;27(10):627-35.

71. Foxman B, Newman M, Percha B, Holmes KK, Aral SO. Measures of sexual partnerships: lengths, gaps, overlaps and sexually transmitted infection. Sex Transm Dis. 2006;33(4):209-14.

72. Krahn M, Guasparini R, Sherman M. Costs and cost-effectiveness of a universal school-based, adolescent hepatitis B vaccination program. Am J Public Health. 1998;88:1638-44. 
73. Guay M, Clouatre A, Blackburn M, Baron G, Wals PD, Roy C. Effectiveness and cost comparison of two strategies for hepatitis $B$ vaccination of schoolchildren. Can J Public Health. 2003;94(1):64-7.

74. Guay M, Blackburn M, Clement P, Tremblay A, St-Hilaire C, Clouatre A. Etude sur les couts et l'efficacite du programme de vaccination des enfants de 0-2 ans au Quebec: Institut national de sante publique du Quebec2006.

75. Gold MR, Siegel JE, Weinstein MC. Cost-effectiveness in health and medicine. Oxford, UK: Oxford University Press; 2001.

76. Colucci R, Hryniuk W, Savage C. HPV vaccination programs in Canada: are we hitting the mark? Report Card on Cancer in Canada2008: 7-10.

77. Laupacis A, Feeny D, Detsky A, Tugwell P. How attractive does a new technology have to be to warrant adoption and utilization? Tenative guidelines for using clinical and economic evaluations. Canadian Med Assoc J. 1992;146:473-81.

78. Lenselink C, Melchers W, Quint W, Hoebers A, Hendriks J, Massuger L, et al. Sexual behaviour and HPV infections in 18 to 29 year old women in the prevaccine era in the Netherlands. PLoS ONE. 2008;3(11):e3743.

79. Sauvageau C, Duval B, Gilca V, Lavoie F, Ouakki M. Human papillomavirus vaccine and cervical cancer screening acceptability among adults in Quebec, Canada. BMC Public Health. 2007;7:304.

80. Bauch C, Rand DA. A Moment Closure Model for Sexually Transmitted Disease Spread Through a Concurrent Partnership Network. Proceedings of the Royal Society of London B. 2000;267:2019-27. 
Table 1: Demographic, transmission, vaccination, and screening-related input parameters.

\begin{tabular}{|c|c|c|c|c|c|c|c|}
\hline $\begin{array}{l}\text { Para- } \\
\text { meter }\end{array}$ & Definition & \multicolumn{5}{|c|}{$\begin{array}{l}\text { Baseline value, or (lower, upper) } \\
\text { for probabilistic uncertainty } \\
\text { analysis }\end{array}$} & Source \\
\hline$\kappa$ & Recruitment rate per year & \multicolumn{5}{|c|}{73,327} & (43) \\
\hline$f, i$ & $\begin{array}{l}\text { Death rate of females per year, by } \\
\text { age group }\end{array}$ & \multicolumn{5}{|c|}{$\begin{array}{l}0.0006,0.00068,0.00118,0.003 \\
0.0076,0.0193,0.0749\end{array}$} & $(43)$ \\
\hline$m, i$ & $\begin{array}{l}\text { Death rate of males per year, by } \\
\text { age group }\end{array}$ & \multicolumn{5}{|c|}{$\begin{array}{l}0.00144,0.00157,0.00225 \\
0.0048,0.0121,0.0315,0.0968\end{array}$} & $(43)$ \\
\hline$h_{\mathrm{i}}$ & Hysterectomy rate per year, by age & \multicolumn{5}{|c|}{$\begin{array}{l}0,0.0027,0.0027,0.0027 \\
0.00603,0.002882,0.00226\end{array}$} & $(44)$ \\
\hline $\begin{array}{l}C \\
i\end{array}$ & $\begin{array}{l}\text { Percentage of cervical cancer } \\
\text { patients dying due to cancer within } \\
5 \text { years, by age group }\end{array}$ & \multicolumn{5}{|c|}{$\begin{array}{l}0.14,0.14,0.14,0.18,0.31,0.45 \\
0.45\end{array}$} & $(45)$ \\
\hline$a_{\mathrm{i}}$ & Ageing rate per year, by age group & \multicolumn{5}{|c|}{$0.2,0.2,0.1,0.1,0.1,0.1,0.1$} & \\
\hline$S_{\mathrm{i}}$ & $\begin{array}{l}\text { Screening rate per year by age } \\
\text { group }\end{array}$ & \multicolumn{5}{|c|}{$\begin{array}{l}(0.13,0.20),(0.30,0.45),(0.28, \\
0.43),(0.26,0.39),(0.23,0.34), \\
(0.17,0.25),(0.04,0.03)\end{array}$} & $(46)$ \\
\hline$P_{\text {false }+}$ & $\begin{array}{l}\text { False positive rate for Pap test } \\
\text { (1-specificity) }\end{array}$ & \multicolumn{5}{|c|}{$(0.026,0.038)$} & $(47)$ \\
\hline$P_{\text {CIN1 }}$ & Sensitivity of pap test for CIN1 & \multicolumn{5}{|c|}{$(0.51,0.80)$} & $\begin{array}{l}(48,63 \\
64)\end{array}$ \\
\hline$P_{\text {CIN2/3 }}$ & Sensitivity of pap test for CIN2/3 & \multicolumn{5}{|c|}{$(0.58,0.85)$} & $\begin{array}{l}(48,63 \\
64)\end{array}$ \\
\hline$P_{\text {cancer }}$ & Sensitivity of pap test for cancer & \multicolumn{5}{|c|}{$(0.65,0.97)$} & $\begin{array}{l}(49,50 \\
63,64)\end{array}$ \\
\hline \multirow[t]{3}{*}{$\begin{array}{l}f \\
i, j\end{array}$} & \multirow{3}{*}{$\begin{array}{l}\text { Proportion of contacts of females } \\
\text { of age group } i \text { that are with males } \\
\text { of age group } j\end{array}$} & & $15-19$ & $20-24$ & $25-34$ & & \multirow[t]{3}{*}{$(38,62)$} \\
\hline & & $\frac{15-19}{20-24}$ & $\begin{array}{ll}0.90 \\
0.10\end{array}$ & $\begin{array}{l}0.10 \\
0.80\end{array}$ & $\begin{array}{ll}0 . \\
0.10\end{array}$ & $\ldots$ & \\
\hline & & $25-34$ & 0 & 0.10 & 0.70 & 0.2 & \\
\hline \multirow{4}{*}{$\begin{array}{l}m \\
i, j\end{array}$} & \multirow{4}{*}{$\begin{array}{l}\text { Proportion of contacts of males of } \\
\text { age group } i \text { that are with females of } \\
\text { age group } j\end{array}$} & & & & & & \\
\hline & & $15-19$ & $\begin{array}{l}15-19 \\
0.95 \\
\end{array}$ & $\begin{array}{l}20-24 \\
0.05 \\
\end{array}$ & $\begin{array}{l}25-34 \\
0 \\
\end{array}$ & $\ldots$ & \multirow[t]{3}{*}{$(38,62)$} \\
\hline & & $20-24$ & 0.10 & 0.85 & 0.05 & & \\
\hline & & $25-34$ & 0 & 0.20 & 0.70 & 0.1 & \\
\hline$b^{16 / 18}$ & $\begin{array}{l}\text { Transmission rate per year for } \\
\text { types } 16 / 18\end{array}$ & \multicolumn{5}{|c|}{$(0.39,0.64)$} & $\begin{array}{l}\text { Fitted } \\
\text { (see 2.6) }\end{array}$ \\
\hline$b^{\text {other }}$ & $\begin{array}{l}\text { Transmission rate per year for } \\
\text { other high-risk types }\end{array}$ & \multicolumn{5}{|c|}{$(0.9,2.1)$} & $\begin{array}{l}\text { Fitted } \\
\text { (see 2.6) }\end{array}$ \\
\hline
\end{tabular}




\begin{tabular}{|c|c|c|c|}
\hline$T_{\mathrm{i}}$ & $\begin{array}{l}\text { Transmission rate adjustment } \\
\text { factor for age }\end{array}$ & $\begin{array}{l}(1.4,1.8),(1.2,2.0),(1.0,1.4), \\
(1.0,1.4),(0.9 .1 .3),(0.9,1.3), \\
(0.9,1.3)\end{array}$ & $\begin{array}{l}\text { Fitted } \\
\text { (see 2.6) }\end{array}$ \\
\hline$F$ & $\begin{array}{l}\text { Transmission rate adjustment } \\
\text { factors for male to female versus } \\
\text { female to male transmission } \\
\text { probabilities }\end{array}$ & $(1.5,1.8)$ & $\begin{array}{l}\text { Fitted } \\
\text { (see 2.6) }\end{array}$ \\
\hline$\chi$ & $\begin{array}{l}\text { Fraction of females infected by } \\
\text { other high-risk types already at } \\
\text { CIN1 due to previous infection by } \\
\text { types } 16 / 18 \text { ("unmasking") }\end{array}$ & 0.000756 & $\begin{array}{l}\text { Estimate } \\
\text { from } \\
(37,52),\end{array}$ \\
\hline$\varepsilon$ & $\begin{array}{l}\text { Vaccine efficacy against infection } \\
\text { by types } 16 / 18 \text { (assumed to be } \\
\text { independent of previous exposure) }\end{array}$ & $(0.9,1.0)$ & $(8,53)$ \\
\hline$\delta$ & $\begin{array}{l}\text { Vaccine efficacy against infection } \\
\text { by other high-risk types }\end{array}$ & $(0.05,0.19)$ & $(8,53)$ \\
\hline$\tau$ & $\begin{array}{l}\text { Rate of waning vaccine-derived } \\
\text { immunity }\end{array}$ & $3 \%$ (for sensitivity analysis only) & Assumed \\
\hline$x_{\text {CIN 2/3 }}^{\text {other }}$ & $\begin{array}{l}\text { Reduction in progression from } \\
\text { CIN1 to CIN23 due to cross- } \\
\text { protection from vaccine }\end{array}$ & $\begin{array}{l}(0.7,0.9) \text { at } 80 \% \text { coverage } \\
(0.74,0.94) \text { at } 60 \% \text { coverage } \\
(0.8,0.99) \text { at } 40 \% \text { coverage }\end{array}$ & $\begin{array}{l}\text { Paramet } \\
\text { erized } \\
\text { from (8) }\end{array}$ \\
\hline
\end{tabular}


Table 2: Natural history parameters

\begin{tabular}{|c|c|c|c|}
\hline Parameter & Definition & $\begin{array}{l}\text { Baseline value, or } \\
\text { (lower, upper) } \\
\text { value }\end{array}$ & Source \\
\hline$d$ & $\begin{array}{l}\text { Proportion of treated CIN2/3 cases who } \\
\text { become susceptible }\end{array}$ & $(0.6,0.9)$ & $(68)$ \\
\hline$c_{f, i}^{I, 16 / 18}$ & Rate at which a female of age group $i$ clears & $(0.23,1.21) / y r$ & $(17)$ \\
\hline$c_{f, i}^{I, \text { other }}$ & 16/18 infection, other high-risk infection & $(0.53,1.79) / y r$ & \\
\hline$c_{m, i}^{I, 16 / 18}$ & Rate at which a male of age group $i$ clears & $(0.23,1.21) / y r$ & $(17)$ \\
\hline$c_{m, i}^{I, \text { other }}$ & 16/18 infection, other high-risk infection & $(0.53,1.79) / y r$ & \\
\hline$c_{f, i}^{L, 16 / 18}$ & Rate at which a female of age group $i$ clears & $(0.19,1.26) / \mathrm{yr}$ & $(17)$ \\
\hline$c_{f, i}^{L, o t h e r}$ & $\begin{array}{l}\text { CIN1 due to } 16 / 18 \text { infection, other high-risk } \\
\text { infection }\end{array}$ & $(0.43,2.12) / y r$ & \\
\hline$c_{f, i}^{H, 16 / 18}$ & Rate at which a female of age group $i$ clears & $(0.14,0.79) / y r$ & $(17)$ \\
\hline$c_{f, i}^{H, o t h e r}$ & $\begin{array}{l}\text { CIN2/3 due to } 16 / 18 \text { infection, other high- } \\
\text { risk infection }\end{array}$ & $(0.31,1.38) / y r$ & \\
\hline $\begin{array}{l}r_{f, i}^{H->I, 16 / 18} \\
r_{f, i}^{H->I, \text { other }}\end{array}$ & $\begin{array}{l}\text { Rate of at which a female of age group } i \\
\text { regresses from CIN } 2 / 3 \text { to infected with } \\
16 / 18 \text {, other high-risk }\end{array}$ & $\begin{array}{l}(0.05,0.71) / \mathrm{yr} \\
(0.04,0.69) / \mathrm{yr}\end{array}$ & $(17)$ \\
\hline $\begin{array}{l}r_{f, i}^{L->I, 16 / 18} \\
r_{f, i}^{L->I, \text { other }}\end{array}$ & $\begin{array}{l}\text { Rate of at which a female of age group } i \\
\text { regresses from CIN1 to infected with 16/18, } \\
\text { other high-risk }\end{array}$ & $\begin{array}{l}(0.15,0.75) / y r \\
(0.15,0.78) / y r\end{array}$ & $(17)$ \\
\hline $\begin{array}{l}r_{f, i}^{H->L, 16 / 18} \\
r_{f, i}^{H->L, o t h e r}\end{array}$ & $\begin{array}{l}\text { Rate of at which a female of age group } i \\
\text { regresses from CIN } 2 / 3 \text { to CIN } 1 \text { due to } 16 / 18 \text {, } \\
\text { other high-risk }\end{array}$ & $\begin{array}{l}(0.01,0.20) / y r \\
(0.01,0.21) / y r\end{array}$ & $(17)$ \\
\hline $\begin{array}{l}p_{f, i}^{I->L, 16 / 18} \\
p_{f, i}^{I->L, o t h e r}\end{array}$ & $\begin{array}{l}\text { Rate of at which a female of age group } i \\
\text { progresses from infected to CIN1 due to } \\
\text { 16/18, other high-risk }\end{array}$ & $\begin{array}{l}(0.03,0.13) / y r \\
(0.03,0.15) / y r\end{array}$ & $(17)$ \\
\hline $\begin{array}{l}p_{f, i}^{L->H, 16 / 18} \\
p_{f, i}^{L->H, \text { other }}\end{array}$ & $\begin{array}{l}\text { Rate of at which a female of age group } i \\
\text { progresses from CIN } 1 \text { to CIN2/3 due to } \\
16 / 18 \text {, other high-risk }\end{array}$ & $\begin{array}{l}(0.03,0.27) / \mathrm{yr} \\
(0.03,0.27) / \mathrm{yr}\end{array}$ & $(17)$ \\
\hline $\begin{array}{l}p_{f, i}^{I->H, 16 / 18} \\
p_{f, i}^{I->H, \text { ther }}\end{array}$ & $\begin{array}{l}\text { Rate of at which a female of age group } i \\
\text { progresses from infected to CIN } 2 / 3 \text { due to } \\
16 / 18 \text {, other high-risk }\end{array}$ & $\begin{array}{l}(0.006,0.134) / \mathrm{yr} \\
(0.003,0.067) / \mathrm{yr}\end{array}$ & $(17)$ \\
\hline $\begin{array}{l}p_{f, i}^{H->C 1,16 / 18} \\
p_{f, i}^{H->C 1, \text { other }}\end{array}$ & $\begin{array}{l}\text { Rate of at which a female of age group } i \\
\text { progresses from CIN } 2 / 3 \text { to cancer, due to } \\
16 / 18 \text {, other high-risk }\end{array}$ & $\begin{array}{l}(0.000927, \\
0.002781) / \mathrm{yr} \\
(0.002,0.038) / \mathrm{yr}\end{array}$ & $(17)$ \\
\hline$f$ & Proportion of cancers due to $16 / 18$ & $(0.7,0.75)$ & $(66)$ \\
\hline \multirow[t]{4}{*}{$\omega$} & Duration of natural immunity & $(2,5)$ yrs & $(39,40)$ \\
\hline & $\begin{array}{l}\text { Calibration target, HPV type } 16 / 18 \text { infection } \\
\text { prevalence in females }\end{array}$ & {$[0.024,0.073]$} & $\begin{array}{l}(1,17 \\
19,41)\end{array}$ \\
\hline & $\begin{array}{l}\text { Calibration target, other high-risk HPV type } \\
\text { infection prevalence in females }\end{array}$ & {$[0.075,0.139]$} & $\begin{array}{l}(1,17 \\
19,41)\end{array}$ \\
\hline & $\begin{array}{l}\text { Calibration target, prevalence of infection in } \\
\text { females with any high-risk HPV type by age }\end{array}$ & $\begin{array}{l}\text { 15-19: }[0.12,0.26] \\
20-24:[0.18,0.40]\end{array}$ & $\begin{array}{l}(1,17 \\
19,41)\end{array}$ \\
\hline
\end{tabular}


25-34: [0.11, 0.23]

45-44: [0.10, 0.22]

45-54: [0.07, 0.16]

55-64: [0.06, 0.13]

Calibration target, incidence of SCC by age per 100,000 females

15-19: $[0,5.5]$

$(1,17$

20-24: $[0.8,11.9]$

$19,41)$

25-34: $[2.8,20.6]$

45-44: [5.1, 25.7]

45-54: $[6.2,27.7]$

55-64: $[5.0,27.3]$ 
Table 3: Cost and disutility parameters.

\begin{tabular}{|c|c|c|c|}
\hline Parameter & Definition & $\begin{array}{l}\text { Baseline value, or } \\
\text { (lower, upper) } \\
\text { value }\end{array}$ & Source \\
\hline$u_{\text {norm }}$ & $\begin{array}{l}\text { Cost per screened female with a normal Pap } \\
\text { test result }\end{array}$ & $\begin{array}{l}(\$ 73.80 \\
\$ 110.78)\end{array}$ & $(54-56)$ \\
\hline$u_{\text {false+ }}$ & $\begin{array}{l}\text { Cost per screened susceptible or infected } \\
\text { female with abnormal (false positive) Pap } \\
\text { result (includes costs for follow-up screening; } \\
\text { does not include cost of initial Pap test) }\end{array}$ & $\begin{array}{l}(\$ 42.70 \\
\$ 241.90)\end{array}$ & $\begin{array}{l}(46,54,55, \\
57,58)\end{array}$ \\
\hline$u_{\text {CIN1 }}$ & $\begin{array}{l}\text { Cost per screened CIN } 1 \text { female with abnormal } \\
\text { Pap result (includes costs for follow-up } \\
\text { screening and treatment of lesions) }\end{array}$ & $(\$ 852, \$ 878)$ & $(20,54)$ \\
\hline$u_{\mathrm{CIN} 2 / 3}$ & $\begin{array}{l}\text { Cost per screened CIN } 2 / 3 \text { female with } \\
\text { abnormal Pap result (includes costs for } \\
\text { follow-up screening and treatment of lesions } \\
\text { or hysterectomy) }\end{array}$ & $(\$ 819, \$ 1,543)$ & $(20,54)$ \\
\hline$u_{\text {cancer }}$ & $\begin{array}{l}\text { Cost per screened cancer female with } \\
\text { abnormal Pap result (includes costs for } \\
\text { follow-up screening and treatment of lesions } \\
\text { or hysterectomy) }\end{array}$ & $\begin{array}{l}(\$ 12,364.92 \\
\$ 22,364.92)\end{array}$ & $(50,54,59)$ \\
\hline$u_{v a c c}$ & Cost of full course of HPV vaccine & $\begin{array}{c}\$ 270 \\
(\$ 90 / \text { dose })\end{array}$ & $(67)$ \\
\hline$u_{\text {clinic }}$ & $\begin{array}{l}\text { Cost of administering HPV vaccine in a clinic } \\
\text { setting, per dose }\end{array}$ & $\begin{array}{l}(\$ 25.00 \\
\$ 35.00)\end{array}$ & $(60)$ \\
\hline$u_{\text {school }}$ & $\begin{array}{l}\text { Cost of administering HPV vaccine in a school- } \\
\text { based setting, per dose }\end{array}$ & $(\$ 9.30, \$ 10.80)$ & $(60)$ \\
\hline $\begin{array}{l}D_{\text {CIN1 }} \\
D_{\text {false }}\end{array}$ & Disutility, false positive or CIN1 diagnosis & $(0,0.06)$ & $(20,36,65)$ \\
\hline$D_{\text {CIN23 }}$ & Disutility, CIN 2/3 & $(0.02,0.12)$ & $(20,36,65)$ \\
\hline $\begin{array}{l}T_{\text {CIN1 }} \\
T_{\text {false }}\end{array}$ & $\begin{array}{l}\text { Duration of disutility, false positive or CIN1 } \\
\text { diagnosis }\end{array}$ & $(0,3)$ months & $(20,36,65)$ \\
\hline$T_{\mathrm{CIN} 2 / 3}$ & Duration of disutility, CIN 2/3 & $(0,5)$ months & $(20,36,65)$ \\
\hline$D_{\text {cancer }}$ & Disutility, cancer diagnosis & $(0.3,0.5)$ & $(20)$ \\
\hline$D_{\text {normal }}$ & Background utilities, by age & $\begin{array}{c}0.94,0.94,0.94 \\
0.935,0.925 \\
0.915,0.900\end{array}$ & $(61)$ \\
\hline
\end{tabular}


Table 4: Strategies evaluated*

\begin{tabular}{|c|l|}
\hline \multicolumn{2}{|l|}{ Compared to a baseline of no immunization: } \\
\hline 1 & Immunizing 80\% of 12-year-old females \\
\hline 2 & Immunizing 80\% of 12-year-old females plus school-based catch-up \\
\hline Compared to a baseline of immunizing 80\% of 12-year-old females: \\
\hline 3 & Baseline plus school-based catch-up covering 80\% of 18-year-old females \\
\hline 4 & Baseline plus clinic-based catch-up covering 40\% of females aged 12-26 \\
\hline 5 & Baseline plus start screening at age 21 \\
\hline 6 & Baseline plus start screening at age 25 \\
\hline 7 & Baseline plus school-based catch-up plus start screening at age 21 \\
\hline 8 & Baseline plus clinic-based catch-up plus start screening at age 25 \\
\hline
\end{tabular}

*current screening rates and age of initial screening assumed except where otherwise noted 
Table 5: Projected costs, health outcomes, and cost-effectiveness ratios.*

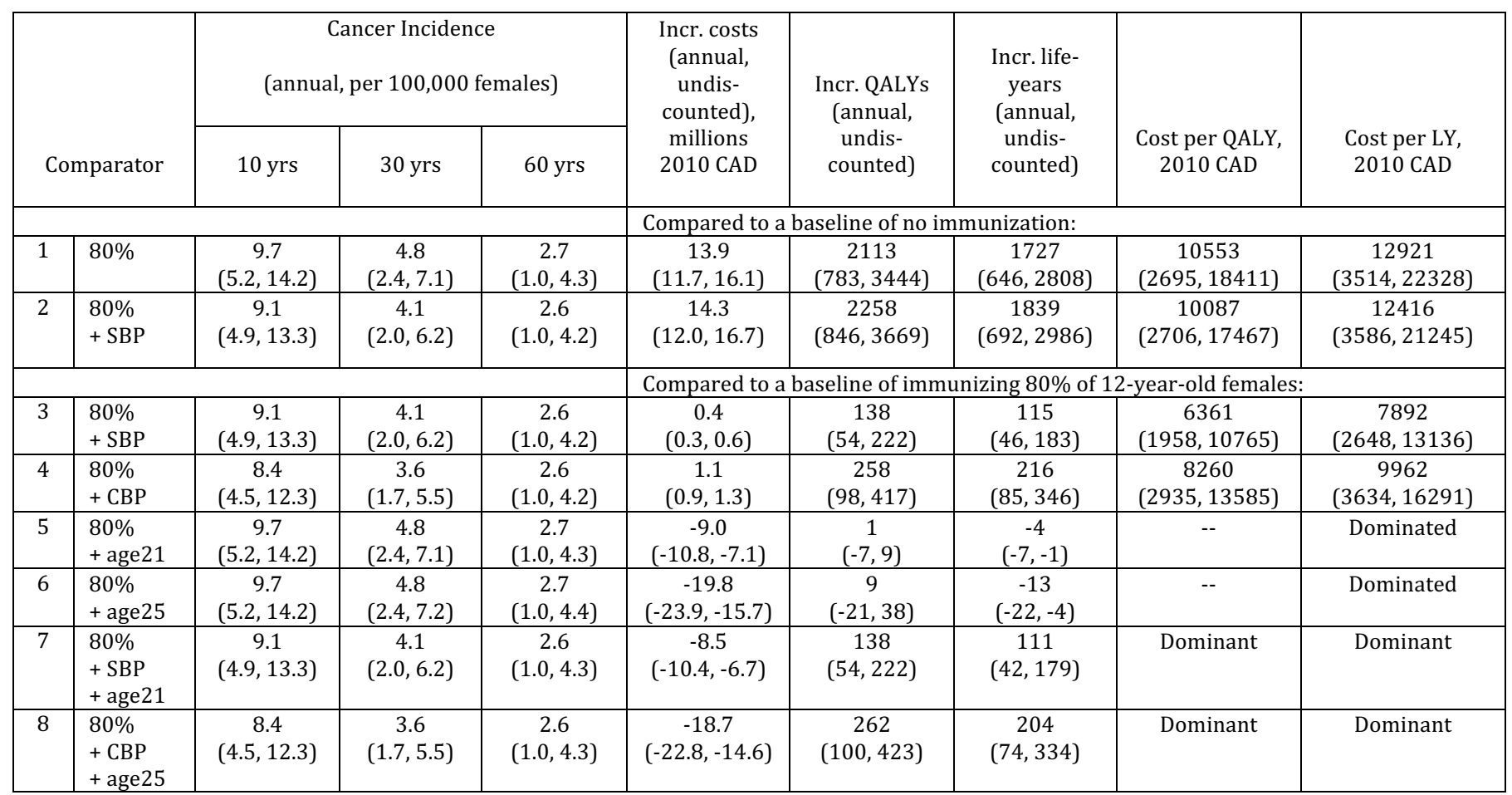

* Values in cells represent the median (median minus two standard deviations, median plus two standard deviations) of accepted realizations from the Monte Carlo-based filtering described in subsection 2.7. 


\section{Figure Captions}

Figure 1: Schematic diagram of dynamic model for female component (a) and male component (b). The state variable $S_{k, F}^{16 / 18}$ (respectively, $I_{k, F}^{16 / 18}, R_{k, F}^{16 / 18}, L_{k, F}^{16 / 18}, H_{k, F}^{16 / 18}, C_{k, F}^{16 / 18}$ , $V_{k, F}^{16 / 18}$ ) is the number of females in age group $k$ who are susceptible (respectively, are infected, are naturally immune, have a low-grade (CIN1) lesion, have a highgrade (CIN2/3) lesion, have squamous cell carcinoma, are protected against infection by the vaccine) for types $16 / 18$. The state variable $S_{k, M}^{16 / 18}$ (respectively, $I_{k, M}^{16 / 18}, R_{k, M}^{16 / 18}$ ) is the number of males in age group $k$ who are susceptible (respectively, infected, naturally immune) for types $16 / 18$. Solid black arrows represent transitions relating to infection or disease status, grey arrows represent deaths, and dashed arrows represent recruitment/aging. Compartments are identical for otherhigh-risk although transition rates differ to capture cross-protection and unmasking as described in Supplementary File Sections S1 and S2. Transition rates between compartments are given in Tables 1-3.

Figure 2: Total incidence of SCC cases per 100,000 females per year over time for $80 \%$ universal vaccination-scenario 1 (a); $80 \%$ universal vaccination plus clinicbased catch-up-scenario 4 (b); 80\% universal vaccination plus start screening at age 25-scenario 6 (c); and 80\% universal vaccination plus clinic-based catch-up plus start screening at age 25-scenario 8 (d). Solid black lines represent median of realizations accepted under the Monte Carlo filtering used in probabilistic uncertainty analysis, and thin grey lines represent plus/minus two standard deviations.

Figure 3: Median incremental cost-effectiveness ratio (ICER) from realizations accepted under the Monte Carlo filtering used in probabilistic uncertainty analysis as a function of cost for 3 doses of vaccine for scenario 1 (baseline strategy), scenario 3 (school-based catch-up program), and scenario 4 (clinic-based catch-up program). 


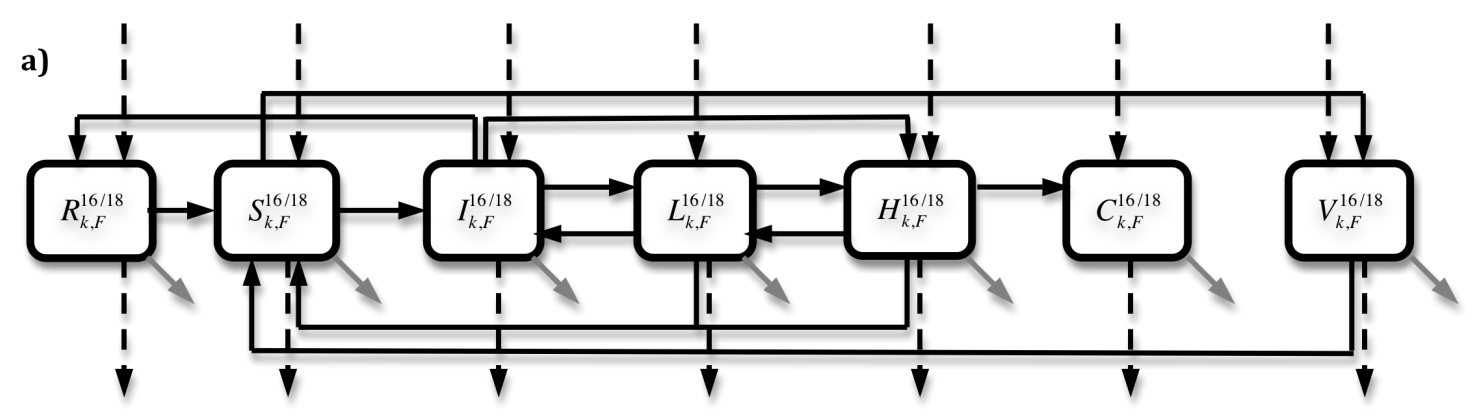

b)

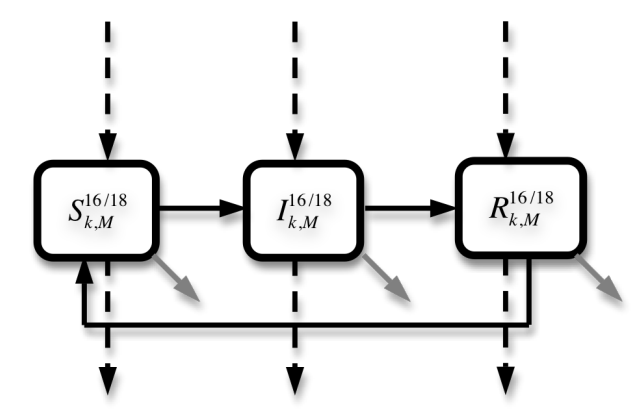

Figure 1 

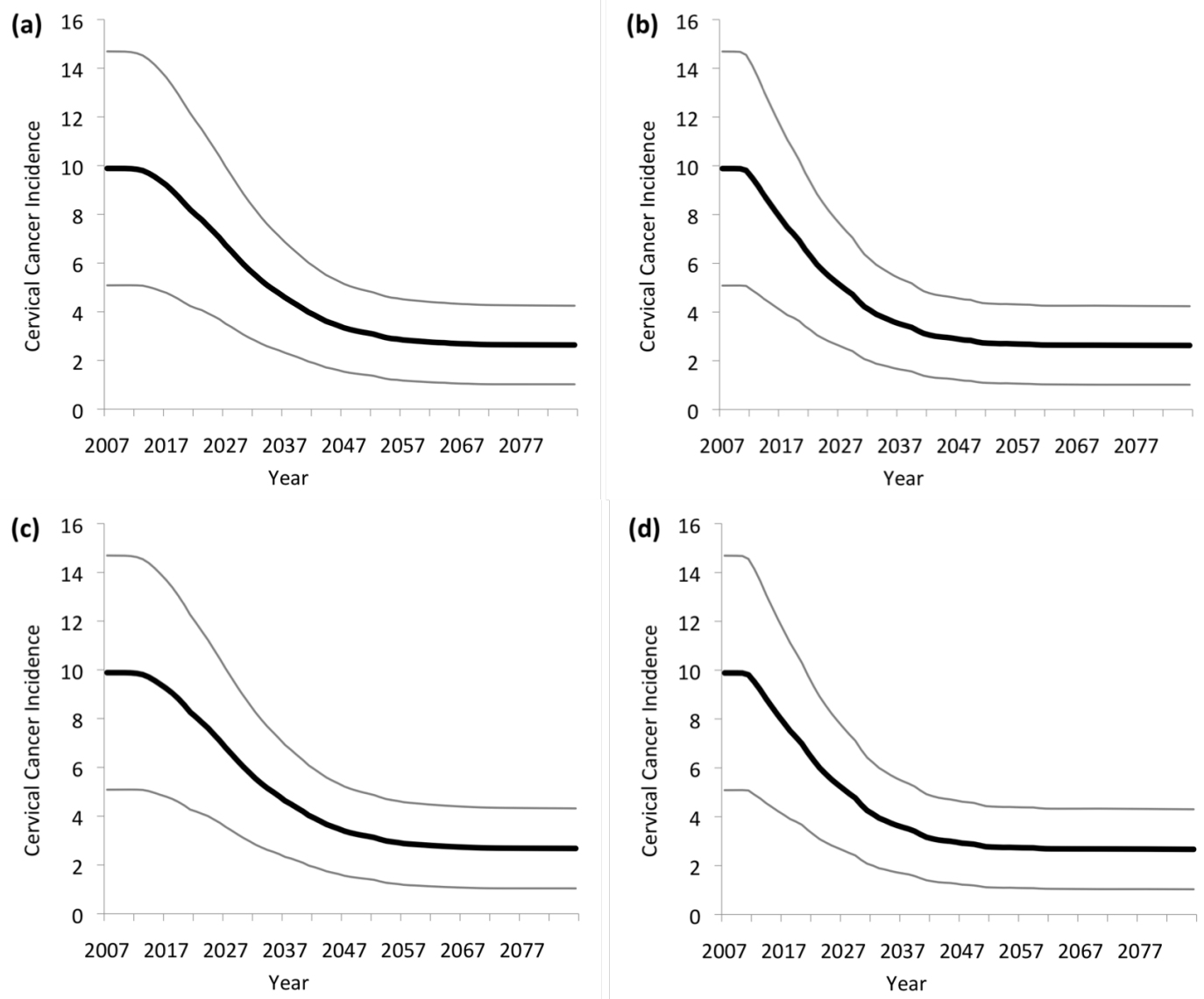

Figure 2 


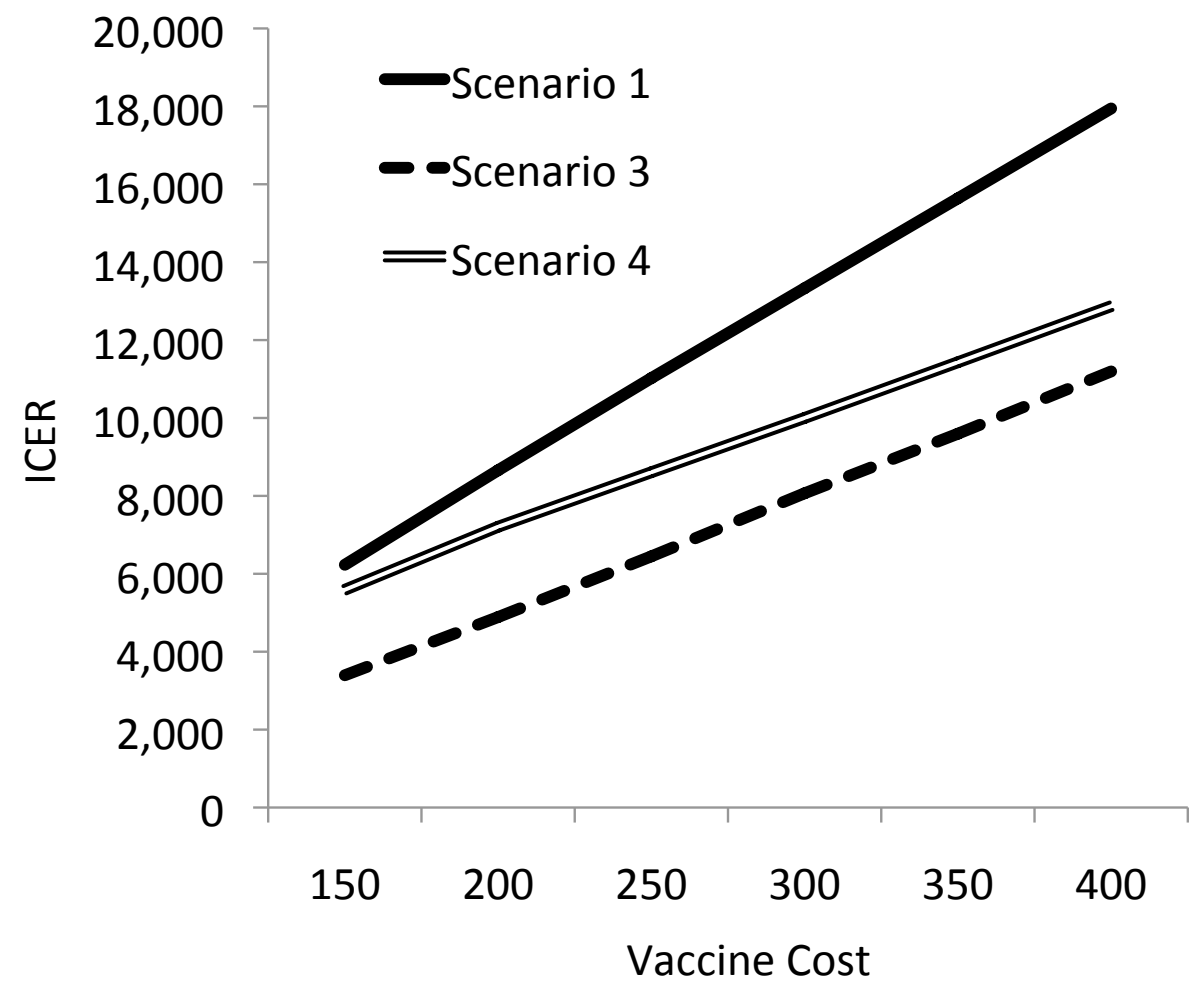

Figure 3 